\title{
Definity Contrast Artifact in Transcranial Doppler Emboli Monitoring
}

Definity (perflutren lipid microsphere) is nonblood-based ultrasound contrast agent approved by the United States Food and Drug Administration for use in patients with suboptimal echocardiograms to improve the delineation of the left ventricular endocardial border. Microspheres are not detectable after $10 \mathrm{~min}$ in most individuals in clinical trials either in the blood or in expired air and concentrations in blood declines in a monoexponential fashion with a mean half-life of $1.3 \mathrm{~min}$. However, Definity contrast might have a longer half-life than suggested and may interfere with transcranial Doppler (TCD) emboli monitoring.

A 38-year-old female with hypertension and postpartum cardiomyopathy presented with focal left-sided neurologic deficits. Initial National Institutes of Health Stroke Scale (NIHSS) score was 16. She received intravenous alteplase. Magnetic resonance imaging brain showed acute right middle cerebral artery (MCA) infarct. Intracranial magnetic resonance angiogram was unremarkable. She underwent 
transthoracic echocardiogram (TTE) and received Definity contrast for the left ventricular endocardial border detection. Two hours after TTE, she underwent continuous TCD [Figure 1a-c] emboli monitoring which showed 535 microembolic events in total in the left MCA and 4 microembolic events in total in the right $\mathrm{MCA}$ detected over $20 \mathrm{~min}$ of monitoring while TCD bubble study did not show the right to left shunting. These TCD microemboli were felt to be artifactual due to possible contamination from Definity contrast performed earlier. Repeat TCD [Figure 1d] emboli monitoring $4 \mathrm{~h}$ after initial test did not show any microembolus.

Contrast-enhanced ultrasound is increasingly used for cardiac and vascular imaging. ${ }^{[1-3]}$ Administration of contrast agent can be used to improve the image quality and it helps to obtain information that cannot be assessed using standard ultrasound. ${ }^{[4,5]}$ Contrast-enhanced ultrasound also allows to characterize the atherosclerotic plaque and helps in the evaluation of plaque ulceration and rupture. To our knowledge, we report the first case of Definity contrast causing delayed TCD emboli monitoring artifact in the absence of the right to left shunting which may indicate a longer washout time of the contrast than estimated. Definity is an ultrasound contrast agent which is used in patients with suboptimal echocardiogram for better delineation of the left ventricular endocardial border which, in turn, helps in accurate assessment of the left ventricular shape and function. Accurate detection of the endocardial border is also important for accurate assessment of systolic left ventricular function and improves the assessment of the left ventricular ejection fraction. ${ }^{[6,7]}$
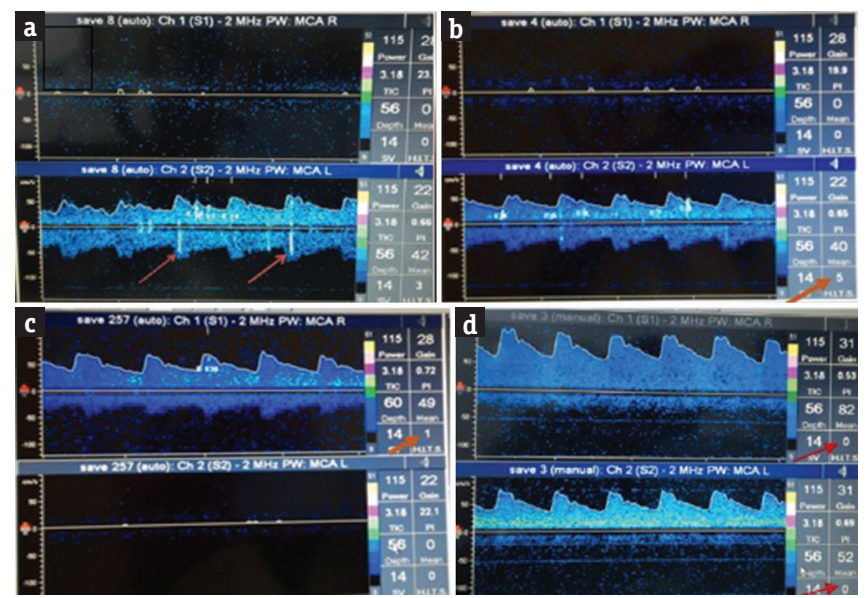

Figure 1: Transcranial Doppler emboli monitoring done $2 \mathrm{~h}$ after Definity contrast showing artifactual embolic hits in the left middle cerebral artery ( $a$ and $b$ ) and right middle cerebral artery (c) distribution. Arrows showing embolic hits as well as the number of embolic hits in a-c. Repeat transcranial Doppler emboli monitoring after $4 \mathrm{~h}$ (d) does not show any embolic hit (arrows)
The Definity contrast upon activation yields a homogeneous, opaque, milky white injectable suspension of perflutren lipid microspheres. This activated Definity (perflutren lipid microspheres) is administered by intravenous injection. The perflutren lipid microspheres, in turn, are composed of octafluoropropane (OFP) encapsulated in an outer lipid shell. Perflutren lipid microspheres exhibit lower acoustic impedance than blood, and these physical acoustic properties of activated Definity provide contrast enhancement of the left ventricular chamber and aid delineation of the left ventricular endocardial border during echocardiography. The main side effects of Definity include hypersensitivity reactions and serious cardiopulmonary reactions. Wei et al. published a multicentric retrospective analysis of 78,383 administered contrast doses in various clinical setting including critically ill patients and found that Definity contrast has a good safety profile. ${ }^{[8]}$ The mean half-life of OFP was $1.9 \mathrm{~min}$ in patients with chronic obstructive pulmonary disease which is almost similar to healthy participants. The pharmacokinetics of activated Definity has not been studied in patients with hepatic diseases or congestive heart failure. Based on this case report, it is imperative to understand the need to delay TCD emboli monitoring in patients with suspected stroke to avoid artifactual emboli hits on TCD monitoring, in patients who have received Definity contrast for echocardiogram. Although the half-life of Definity contrast is thought to be in minutes, it might take longer to metabolize especially in patients with congestive heart disease and hepatic and pulmonary disease.

\section{Declaration of patient consent}

The authors certify that they have obtained all appropriate patient consent forms. In the form the patient(s) has/have given his/her/their consent for his/ her/their images and other clinical information to be reported in the journal. The patients understand that their names and initials will not be published and due efforts will be made to conceal their identity, but anonymity cannot be guaranteed.

\section{Financial support and sponsorship}

Nil.

\section{Conflicts of interest}

There are no conflicts of interest.

Ramnath Santosh Ramanathan

Neurology Department, Akron Neurology Inc., Akron, Ohio, USA

Address for correspondence: Dr. Ramnath Santosh Ramanathan, Akron Neurology Inc., 3632 Ridgewood Road, Akron, Ohio 44333, USA. E-mail: dr.santosh7@gmail.com 


\section{REFERENCES}

1. ten Kate GL, Sijbrands EJ, Staub D, Coll B, ten Cate FJ, Feinstein SB, et al. Noninvasive imaging of the vulnerable atherosclerotic plaque. Curr Probl Cardiol 2010;35:556-91.

2. Feinstein SB, Coll B, Staub D, Adam D, Schinkel AF, ten Cate FJ, et al. Contrast enhanced ultrasound imaging. J Nucl Cardiol 2010;17:106-15.

3. Staub D, Schinkel AF, Coll B, Coli S, van der Steen AF, Reed JD, et al. Contrast-enhanced ultrasound imaging of the vasa vasorum: From early atherosclerosis to the identification of unstable plaques. JACC Cardiovasc Imaging 2010;3:761-71.

4. Mulvagh SL, Rakowski H, Vannan MA, Abdelmoneim SS, Becher H, Bierig SM, et al. American society of echocardiography consensus statement on the clinical applications of ultrasonic contrast agents in echocardiography. J Am Soc Echocardiogr 2008;21:1179-201.

5. Senior R, Becher H, Monaghan M, Agati L, Zamorano J, Vanoverschelde JL, et al. Contrast echocardiography: Evidence-based recommendations by European Association of Echocardiography. Eur J Echocardiogr 2009;10:194-212.

6. Hoffmann R, Barletta G, von Bardeleben S, Vanoverschelde JL, Kasprzak J, Greis C, et al. Analysis of left ventricular volumes and function: A multicenter comparison of cardiac magnetic resonance imaging, cine ventriculography, and unenhanced and contrast-enhanced two-dimensional and three-dimensional echocardiography. J Am Soc Echocardiogr 2014;27:292-301.

7. Kurt M, Shaikh KA, Peterson L, Kurrelmeyer KM, Shah G,
Nagueh SF, et al. Impact of contrast echocardiography on evaluation of ventricular function and clinical management in a large prospective cohort. J Am Coll Cardiol 2009;53:802-10.

8. Wei K, Mulvagh SL, Carson L, Davidoff R, Gabriel R, Grimm RA, et al. The safety of deFinity and Optison for ultrasound image enhancement: A retrospective analysis of 78,383 administered contrast doses. J Am Soc Echocardiogr 2008;21:1202-6.

This is an open access journal, and articles are distributed under the terms of the Creative Commons Attribution-NonCommercial-ShareAlike 4.0 License, which allows others to remix, tweak, and build upon the work non-commercially, as long as appropriate credit is given and the new creations are licensed under the identical terms.

\begin{tabular}{|l|l|}
\hline \multicolumn{2}{|c|}{ Access this article online } \\
\hline Quick Response Code: & Website: \\
\hline & www.ruralneuropractice.com \\
\cline { 2 - 2 } & \\
& \\
\hline
\end{tabular}

How to cite this article: Ramanathan RS. Definity contrast artifact in transcranial Doppler emboli monitoring. J Neurosci Rural Pract 2018;9:284-6. 